\title{
In Situ Structural Characterization of Glycerophospholipids and Sulfatides in Brain Tissue Using MALDI-MS/MS
}

\author{
Shelley N. Jackson, Hay-Yan J. Wang, and Amina S. Woods \\ Intramural Research Program, National Institute on Drug Abuse, National Institutes of Health, Baltimore, \\ Maryland, USA
}

\begin{abstract}
Lipids are major structural components of biomembranes. Negatively charged species such as phosphatidylinositol, phosphatidylserine, sulfatides, and the zwitterionic phosphatidylethanolamines are major components of the cytoplasmic surface of the cellular membrane lipid bilayer and play a key role in several receptors signaling functions. Lipids are not just involved in metabolic and neurological diseases; negatively charged lipids in particular play crucial roles in physiological events such as signal transduction, receptors, and enzymatic activation, as well as storage and release of therapeutic drugs and toxic chemicals in the body. Due to the importance of their role in signaling, the field of lipidomics has rapidly expanded in recent years. In the present study, direct probing of tissue slices with negative ion mode matrix assisted laser desorption/ionization mass spectrometry was employed to profile the distribution of lipids in the brain. In total, 32 lipid species consisting of phosphatidylethanolamines, phosphatidylglycerol, phosphatidylinositols, phosphatidylserines, and sulfatides were assigned. To confirm the structure of lipid species, MALDI-MS/MS analysis was conducted. Product-ion spectra obtained in negative ion mode allow for the assignment of the head groups and the fatty acid chains for the lipid species. (J Am Soc Mass Spectrom 2007, 18, 17-26) ( 2007 American Society for Mass Spectrometry
\end{abstract}

$\mathrm{A}$ fter water, lipids are the most common biomolecules found in the brain and account for almost half of the brain dry weight [1]. They are major structural components of biomembranes and play a key role in signaling functions in the body. Due to their role in signaling, the field of lipidomics has grown rapidly in recent years and has been the subject of several reviews [2-5]. Furthermore, altered levels of lipids in brain tissue have been observed with several diseases such as Alzheimer's disease, neuronal ceroid-lipofuscinosis, and Niemann-Pick disease [6-9]. Two major groups of complex lipids in the brain are glycerophospholipids, consisting of phosphatidylcholines (PC), phosphatidylethanolamines (PE), phosphatidylinositols (PI), phosphatidylserines (PS), phosphatidylglycerol (PG) etc. ... and sphingolipids, consisting of cerebrosides, sphingomyelin (SM), sulfatides (ST), and gangliosides.

Traditional methods for the analysis of lipids in tissue by mass spectrometry involve tissue homogenization and extraction with possible purification before mass analysis [10]. Matrix-assisted laser desorption/ ionization (MALDI) mass spectrometry has become a useful technique for the direct analysis of large biomol-

Published online September 26, 2006

Address reprint requests to Dr. A. S. Woods, Intramural Research Program, National Institute on Drug Abuse, National Institutes of Health, 5500 Nathan Shock Drive, Baltimore, MD 21224, USA. E-mail: awoods@intra.nida.nih.gov ecules, peptides, and proteins from tissue [11-13]. Direct tissue analysis using MALDI produces mass spectral profiles, which can be employed to map the location of molecules in tissue. In this technique, matrix is deposited directly onto a tissue section and then massanalyzed, eliminating the time-consuming extraction step in traditional methods for tissue analysis. Furthermore, by eliminating the need for tissue homogenization and analyte extraction, direct tissue analysis by MALDI improves spatial resolution and reduces sample consumption compared with traditional methods.

Recently, several studies [14-18] have been conducted using MALDI-MS to profile lipids, in particular phospholipids, directly from tissue. MALDI time-offlight mass spectrometry (TOFMS) has been employed to analyze phospholipids in thin sections of lens [14], leg muscle [15], and brain tissue [16, 17]. In most of these studies, analysis was conducted in positive ion mode and focused on the profiling of PC and SM species. However, the use of negative ion mode has been used to profile PI, ST, and ganglioside species in brain tissue sections [17]. MALDI Fourier transform mass spectrometry (FTMS) has also been used to characterize phospholipids in mammalian tissue [18]. To gain more structural information, tandem mass spectrometry has been utilized for the direct analysis of PC species in tissue. In one study, a MALDI-TOF/TOF mass spectrometer was employed for the in situ structural characterization of PCs in brain tissue [19]. In this 
work, protonated, sodiated, potassiated, and lithiated PC species were analyzed by tandem MS and yielded fragment peaks corresponding to the phosphocholine head group. However, only lithiated PC species yielded fragment peaks permitting the identification of acyl substituents. Another study employed a MALDI linear ion trap mass spectrometer for the direct analysis of PC species in spinal cord and $\mathrm{MS}^{\mathrm{n}}$ analysis yielded fragments corresponding to the phosphocholine head group [20].

In the present work, direct tissue analysis of glycerophospholipids and sulfatides in rat brain tissue was performed using a MALDI-TOF/TOF mass spectrometer. To cancel the innate advantage that PC and SM species have in positive ion mode due to the presence of a quarternary amine, analysis was conducted in negative ion mode. Tandem MS analysis of PE, PS, PI species produced fragment peaks, which allowed for the assignment of head groups specific for each lipid class and acyl/alkenyl groups for individual lipid species. Product-ion spectra of PE species permitted the assignment of both diacyl and plasmalogen species. Tandem MS analysis of ST species yielded fragment peaks corresponding to the ST head group and for hydroxyl ST species a fragment peak, permitting the assignment of the acyl group was also recorded.

\section{Methods}

\section{Mass Spectrometer}

A MALDI-TOF/TOF (4700 Proteomics Analyzer, Applied Biosystems, Framingham, MA) with a Nd:YAG laser $(355 \mathrm{~nm})$ at a repetition rate of $200 \mathrm{~Hz}$ was used in this study for both MS and MS/MS analysis in negative ion mode as previously described [21]. For MS analysis, mass spectra were acquired in reflectron mode and were the sum of 400 laser shots. For MS/MS analysis, mass spectra were the sum of 1000 laser shots and a collision energy of $1 \mathrm{keV}$ with air as the collision gas was used to induce fragmentation. The following lipid standards: brain phosphatidylethanolamines $(99 \%$, porcine, Avanti Polar Lipids, Alabaster, AL), phosphatidylserines (99\%, porcine, Avanti Polar Lipids), cerebroside sulfatides (99\%, porcine, Avanti Polar Lipids), and polar lipid extract (porcine, Avanti Polar Lipids) were used to calibrate the mass spectrometer.

\section{Tissue Sectioning}

All the animal use and handling in this work abides by the Guide for the Care and Use of Laboratory Animals (NIH). Male Sprague-Dawley rats (300-420 × g Harlan Industries, Indianapolis, IN) were euthanized by an intraperitoneal injection of sodium pentobarbital $(>65$ $\mathrm{mg} / \mathrm{kg}$ ). The brains were immediately frozen in dry ice-chilled isopentane for $15 \mathrm{~s}$ and stored at $-80-\mathrm{C}$. Brain tissue was cut into thin sections (14 $\mu \mathrm{m}$ thickness) in a cryostat (CM 3050 S; Leica Microsystems Nussloch
$\mathrm{GmbH}$, Nussloch, Germany). Serial brain sections were alternately placed onto a MALDI sample target and poly-L-lysine coated microscopic slide. The tissue sections on the microscopic slides were stained with cresyl violet and a Rat Brain Atlas [22] was used for the assignment of the brain region analyzed by mass spectrometry.

\section{Sample Preparation}

The MALDI matrix used in this study was 2,6dihydroxyacetophenone, DHA, (Fluka, Buchs, Switzerland). In a previous study, DHA was used at a concentration of $10 \mathrm{mg} / \mathrm{mL}$ [17]. However, due to the sublimation of DHA under high vacuum, in this study DHA was prepared in $50 \%$ ethanol at a concentration of 30 $\mathrm{mg} / \mathrm{mL}$. In this work, the amount of DHA deposited allowed for the acquisition of data for over $30 \mathrm{~min}$. For tissue analysis, $0.1 \mu \mathrm{L}$ of matrix solution was deposited directly on the section, resulting in a matrix spot size between 800 and $1500 \mu \mathrm{m}$, and allowed to air-dry before insertion into the mass spectrometer.

\section{Lipid Assignment}

In MALDI-TOF mass spectra, PG, PI, and PS species number equal the total length and number of double bonds of both acyl chains, while ST species number corresponds to the length and number of double bonds of the acyl chain attached to the sphingosine base. PE species number equal the total length and number of both radyl chains with a representing 1,2 diacyl species and $\mathbf{p}$ representing a 1-O-(1'-alkenyl)-2-acyl (plasmalogen) species. Assignment of phospholipid species based upon product-ion spectra is as follows: PL sn-1 acyl/ alkenyl group/sn-2 acyl group, while assignment of sulfatides species based upon product-ion spectra is as follows. ST dihydroxy long-chain base (dLCB):fatty acid (FA) with a $h$ representing $\alpha$-hydroxyl substituents on the fatty acid chain.

\section{Results and Discussion}

Initial experiments were conducted in negative ion mode by MALDI-TOFMS with DHA matrix. Figure 1 illustrates mass spectra of lipid species in the rat brain from the (a) cerebellar cortex (mostly gray matter), (b) cerebellar peduncle (mostly white matter), and (c) cerebral caudate-putamen (mixture of gray/white matter), Table 1 lists mass peak assignments for lipid species from mass spectra of the three regions. In total, 32 species of lipids consisting of 11 PEs, 2 PGs, 2 PIs, 8 PSs, and 9 STs were assigned. However, it should be noted that for some mass peaks more than one lipid species is possible. In these cases, the major lipid specie was determined by MS/MS, which will be discussed below, and are represented in bold text in Table 1 . When compared with our previous work [17] using DHB as a matrix, more classes of phospholipids (PEs and PSs) 

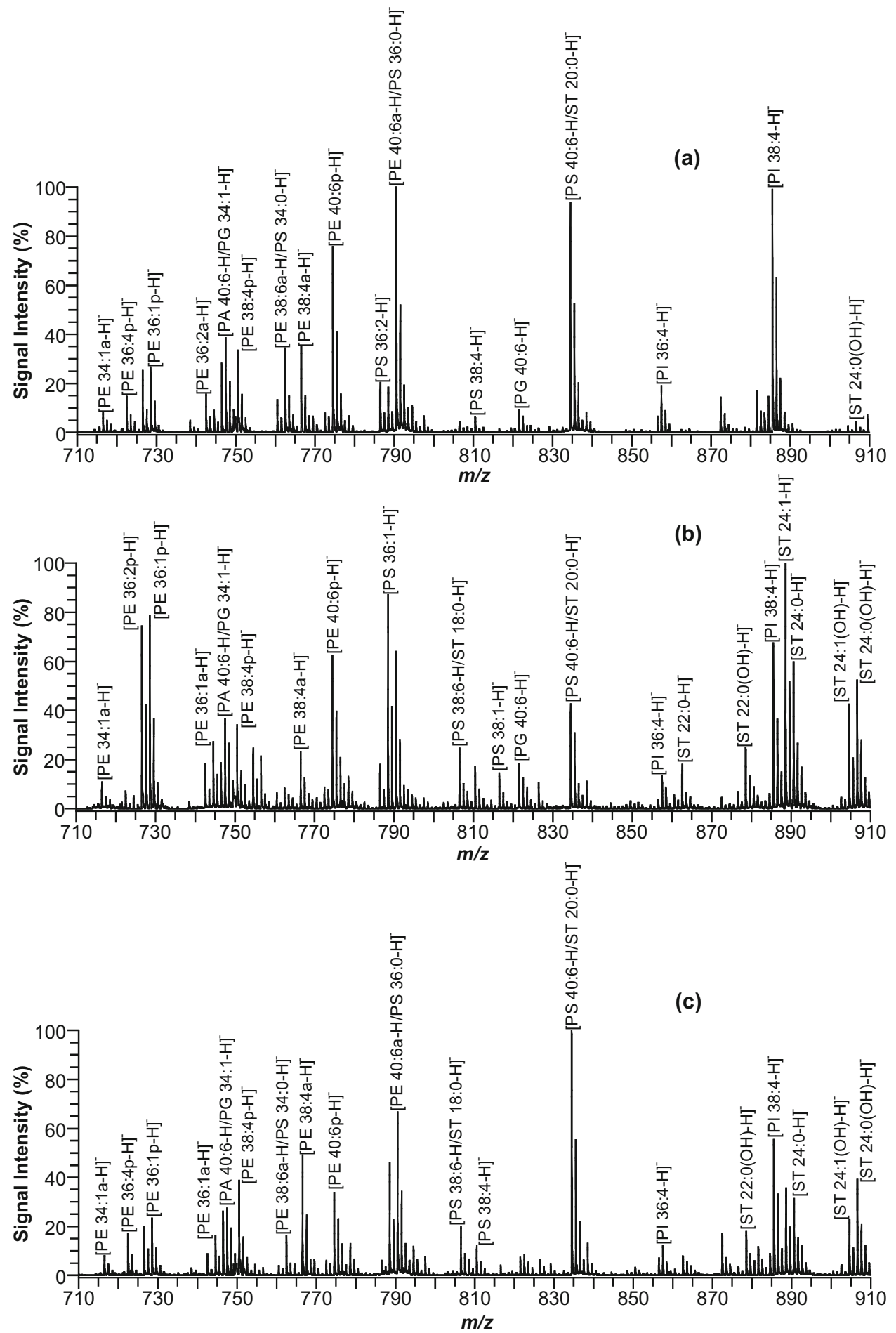

Figure 1. MALDI mass spectra of (a) cerebellar cortex, (b) cerebellar peduncle, and (c) cerebral caudate-putamen with DHA matrix in negative ion mode.

were observed. However, in agreement with our previous study, similar abundance of ST species in white matter compared to the gray matter region were seen. In one recent study, secondary ion mass spectrometry (SIMS) has been used to map lipids in mouse brain sections in negative ion mode [23]. In the SIMS study, the ion peak [PI 38:4-H] $]^{-}$was mapped and shown to be predominant in gray matter regions, which is in agreement with the mass spectra illustrated in Figure 1. Also there is good agreement between the ST species detected by SIMS and the ST species detected by MALDI in Figure 1. However, the mapping of ST species by SIMS recorded higher abundance of ST species in gray matter as compared to white matter, which is in con- 
Table 1. Mass peak assignments for lipid species in negative ion MS mode

\begin{tabular}{|c|c|c|c|c|}
\hline Species $^{\mathrm{ab}}$ & {$[\mathrm{M}-\mathrm{H}]^{-}(\mathrm{Da})^{\mathrm{c}}$} & Cerebellar cortex & Cerebellar peduncle & Cerebral caudate-putamen \\
\hline PE 34:1a & 716.52 & 716.55 & 716.53 & 716.53 \\
\hline PE $36: 4 p$ & 722.51 & 722.53 & 722.51 & 722.51 \\
\hline PE $36: 2 p$ & 726.54 & 726.56 & 726.54 & 726.55 \\
\hline PE $36: 1 p$ & 728.56 & 728.58 & 728.56 & 728.56 \\
\hline PE $36: 2 a$ & 742.54 & 742.55 & 742.54 & 742.54 \\
\hline PE 36:1a & 744.55 & 744.57 & 744.55 & 744.56 \\
\hline PG $34: 1^{d}$ & 747.52 & 747.53 & 747.52 & 747.52 \\
\hline PE $38: 4 p$ & 750.54 & 750.56 & 750.54 & 750.55 \\
\hline PE 38:6a & 762.51 & 762.52 & 762.51 & 762.51 \\
\hline PS 34:0 & 762.53 & & & \\
\hline PE 38:4a & 766.54 & 766.55 & 766.54 & 766.54 \\
\hline PE 40:6p & 774.54 & 774.55 & 774.54 & 774.55 \\
\hline PS $36: 2$ & 786.53 & 786.54 & 786.53 & 786.53 \\
\hline PS 36:1 & 788.54 & 788.55 & 788.54 & 788.55 \\
\hline PE 40:6a & 790.54 & 790.55 & 790.54 & 790.54 \\
\hline PS 36:0 & 790.56 & & & \\
\hline ST $18: 0$ & 806.55 & 806.54 & 806.55 & 806.54 \\
\hline PS 38:6 & 806.50 & & & \\
\hline PS $38: 4$ & 810.53 & 810.53 & 810.52 & 810.53 \\
\hline PS $38: 1$ & 816.58 & - & 816.56 & 816.56 \\
\hline PG 40:6 & 821.53 & 821.54 & 821.54 & 821.53 \\
\hline ST 18:0 (OH) & 822.54 & 822.55 & 822.54 & 822.54 \\
\hline PS 40:6 & 834.53 & 834.53 & 834.54 & 834.53 \\
\hline ST20:0 & 834.58 & & & \\
\hline PI 36:4 & 857.52 & 857.51 & 857.52 & 857.52 \\
\hline ST 22:0 & 862.61 & - & 862.60 & 862.60 \\
\hline ST 22:0 (OH) & 878.60 & - & 878.60 & 878.59 \\
\hline PI 38:4 & 885.55 & 885.55 & 885.55 & 885.55 \\
\hline ST $24: 1$ & 888.62 & 888.60 & 888.62 & 888.62 \\
\hline ST $24: 0$ & 890.64 & 890.63 & 890.63 & 890.63 \\
\hline ST $24: 1(\mathrm{OH})$ & 904.62 & 904.60 & 904.62 & 904.61 \\
\hline ST $24: 0(\mathrm{OH})$ & 906.63 & 906.62 & 906.63 & 906.63 \\
\hline
\end{tabular}

${ }^{a}$ PG, PI, PS species number equal the total length and number of double bonds of both acyl chains. PE species number equal the total length and number of double bonds of both radyl chains with a and p denoting diacyl and plasmalogen species respectively. ST species number corresponds to the length and number of double bonds of the acyl chain attached to the sphingosine base.

${ }^{b}$ Species appearing in bold represent the major species confirmed present by MS/MS analysis at the listed $\mathrm{m} / \mathrm{z}$ value.

${ }^{c}$ Masses are theoretical monoisotopic.

dTentative assignment.

trast to the results in this study. This contrasting result may be attributed to the inherent difference between ionization by MALDI and SIMS. Another possible explanation is that in MALDI addition of the matrix solution which contains ethanol to the tissue section might cause extraction of some of the lipids located beneath the surface of the tissue while SIMS is mainly detecting the lipids on the surface of the tissue sections. Comparing mass spectra of gray (Figure 1a) and white matter (Figure 1b), PE species show a higher relative abundance of plasmalogen species in white than in gray matter. This is in agreement with previous studies, which have shown that PE plasmalogen species are concentrated in myelin and white matter regions of the brain [24-26]. Furthermore, in a previous study using ESI-MS to analyze PE species in extracts of human brain gray and white matter [26], the dominant mass peaks detected in gray matter were PE 40:6a, PE 40:6p, and PE $38: 4 \mathrm{p}$ while in white matter the major mass peak recorded was PE 36:2p. Additionally, tandem MS analysis of PE species illustrated that in white matter the acyl group at the sn-2 position is mostly monounsaturated while in gray matter the acyl group at the sn-2 position is mostly polyunsaturated. Both of these results are similar to the data obtained in this work for rat brain gray and white matter regions. In Figure 1a (a gray matter region) the two most abundant PE species are PE 40:6a and PE 40:6p while in Figure 1b (a white matter region) the two most abundant PE species are PE 36:2p and PE 36:1p. Tandem MS results discussed below and listed in Table 2 showed that the acyl group at the sn-2 position in PE 40:6a and PE 40:6p is 22:6 (polyunsaturated) while the acyl group at the sn-2 position in PE 36:2p and PE 36:1p is 18:1 (monounsaturated).

Phosphatidylethanolamines are one of the most abundant glycerophospholipid classes in the brain. In addition to the basic diacyl species of glycerophospholipids, in which two acyl groups are attached to the sn-1 and sn-2 position of the glycerol backbone, PE also contains plasmalogen species, in which a vinyl ether group instead of an acyl group is attached to the sn- 1 
Table 2. Assignment of lipid molecular species in MS/MS negative ion mode

\begin{tabular}{|c|c|c|c|}
\hline Class & $m / z$ & MS/MS Peaks & Molecular species \\
\hline \multirow[t]{11}{*}{ PE } & 716.5 & 281,255 & 1-acyl-2-acyl, 16:0-18:1 \\
\hline & 722.5 & 303,180 & 1-alkenyl-2-acyl, 16:0-20:4 \\
\hline & 726.5 & $462,444,281$ & 1-alkenyl-2-acyl, 18:1-18:1 \\
\hline & 728.6 & 464,281 & 1-alkenyl-2-acyl, 18:0-18:1 \\
\hline & 742.5 & 478,281 & 1-acyl-2-acyl, 18:1-18:1 \\
\hline & 744.6 & $480,283,281$ & 1-acyl-2-acyl, 18:0-18:1 \\
\hline & 750.5 & $464,446,303$ & 1-alkenyl-2-acyl, 18:0-20:4 \\
\hline & 762.5 & $452,435,327,255$ & 1-acyl-2-acyl, 16:0-22:6 \\
\hline & 766.5 & $480,303,283$ & 1-acyl-2-acyl, 18:0-20:4 \\
\hline & 774.5 & $464,446,327$ & 1-alkenyl-2-acyl, 18:0-22:6 \\
\hline & 790.5 & $524,506,480,462,327,283$ & 1-acyl-2-acyl, 18:0-22:6 \\
\hline \multirow[t]{2}{*}{$\mathrm{PI}$} & 857.5 & $553,391,303,255,241$ & 1-acyl-2-acyl, 16:0-20:4 \\
\hline & 885.5 & $581,419,303,283,259,241,223$ & 1-acyl-2-acyl, 18:0-20:4 \\
\hline \multirow[t]{6}{*}{ PS } & 762.5 & $675,437,419,283,255$ & 1-acyl-2-acyl, 18:0-16:0ª \\
\hline & 786.5 & $699,417,281$ & 1-acyl-2-acyl, 18:1-18:1 \\
\hline & 788.5 & $701,419,283,281$ & 1-acyl-2-acyl, 18:0-18:1 \\
\hline & 810.5 & $723,419,303,283$ & 1-acyl-2-acyl, 18:0-20:4 \\
\hline & 816.6 & $729,419,309,283$ & 1-acyl-2-acyl, 18:0-20:1 \\
\hline & 834.5 & $747,463,437,419,327,283$ & 1-acyl-2-acyl, 18:0-22:6 \\
\hline \multirow[t]{7}{*}{ ST } & 806.5 & $257,241,97,80$ & - \\
\hline & 862.6 & $257,241,97,80$ & - \\
\hline & 878.6 & $540,398,300,257,241,97,80$ & dLCB/hFA, 18:1-22:0 \\
\hline & 888.6 & $398,300,257,241,97,80$ & - \\
\hline & 890.6 & $398,300,257,241,97,80$ & - \\
\hline & 904.6 & $540,398,300,257,241,97,80$ & dLCB/hFA, 18:1-24:1 \\
\hline & 906.6 & $540,398,300,257,241,97,80$ & dLCB/hFA, 18:1-24:0 \\
\hline
\end{tabular}

aTentative assignment.

position. Plasmalogen species are a major constituent of brain PE, accounting for $\sim 60 \%$ of $\mathrm{PE}$ in the human adult brain [1]. Figure 2a illustrates product-ion spectra of PE 40:6a-H from the cerebellar cortex in negative ion mode with DHA matrix. Structural information enabling the identification and positional assignment of the acyl groups in the PE species is provided by the mass peaks at 524, 506, 480, 462, 327, $283 \mathrm{Da}$. These mass peaks are attributed to the loss of the acyl group at sn-1 as a ketene, the loss of the acyl group at sn-1, the loss of the acyl group at sn-2 as a ketene, the loss of the acyl group at sn-2, docosahexaenate (22:6) anion, and stearate (18:0) anion and are assigned as follows: 524 [M-H$\left.\mathrm{R}_{1}{ }^{\prime} \mathrm{CH}=\mathrm{C}=\mathrm{O}\right]^{-}, 506\left[\mathrm{M}-\mathrm{H}-\mathrm{R}_{1} \mathrm{CO}_{2} \mathrm{H}\right]^{-}, 480[\mathrm{M}-\mathrm{H}-$ $\left.\mathrm{R}_{2}{ }^{\prime} \mathrm{CH}=\mathrm{C}=\mathrm{O}\right]^{-}, 462\left[\mathrm{M}-\mathrm{H}-\mathrm{R}_{2} \mathrm{CO}_{2} \mathrm{H}\right]^{-}, 327$ $\left[\mathrm{C}_{22} \mathrm{H}_{31} \mathrm{O}_{2}\right]^{-}, 283\left[\mathrm{C}_{18} \mathrm{H}_{35} \mathrm{O}_{2}\right]^{-}$. Based upon the fragment peaks observed in Figure $2 \mathrm{a}$, the PE specie was assigned as PE 18:0a/22:6. The positional assignments of acyl groups accordingly as sn- 1 or sn- 2 substituent is based upon previous fragmentation studies [27-29] of PE diacyl species, in which the $\mathrm{R}_{2} \mathrm{CO}_{2}{ }^{-}$ion is more abundant than the $\mathrm{R}_{1} \mathrm{CO}_{2}{ }^{-}$ion and the abundance of ions corresponding to the loss of the sn-2 substituent is greater than the abundance of ions reflecting the loss of the sn-1 substituent.

Figure $2 \mathrm{~b}$ illustrates a product-ion spectrum of PE 40:6p-H from the cerebellar cortex in negative ion mode with DHA matrix. In Figure $2 b$, only mass peaks associated with the fragmentation of the acyl group at the sn- 2 position were observed. These mass peaks are attributed to the loss of the acyl group at sn-2 as a ketene, the loss of the acyl group at sn-2, docosahexaenate (22:6) anion, and are assigned as follows: 464 $\left[\mathrm{M}-\mathrm{H}-\mathrm{R}_{2}{ }^{\prime} \mathrm{CH}=\mathrm{C}=\mathrm{O}^{-}, 446\left[\mathrm{M}-\mathrm{H}-\mathrm{R}_{2} \mathrm{CO}_{2} \mathrm{H}\right]^{-}, 327\right.$ $\left[\mathrm{C}_{22} \mathrm{H}_{31} \mathrm{O}_{2}\right]^{-}$. Based upon the fragment peaks observed in Figure $2 b$, the PE specie was assigned as PE 18:0p/ 22:6. Previous fragmentation studies of PE plasmalogen species, have produced similar results in which little to no fragmentation occurs at the vinyl - ether bond at the sn-1 position [27, 28].

Figure 2c shows a product-ion spectrum of PE 34: $1 \mathrm{a}-\mathrm{H}$ from the cerebral caudate-putamen in negative ion mode with DHA matrix. Two fragment peaks, corresponding to the acyl groups, are observed and are assigned as follows: 281 oleate $(18: 1)$ anion $\left[\mathrm{C}_{18} \mathrm{H}_{33} \mathrm{O}_{2}\right]^{-}$ and 255 palmitate (16:0) anion $\left[\mathrm{C}_{16} \mathrm{H}_{31} \mathrm{O}_{2}\right]^{-}$. Based upon the fragment peaks observed in Figure $2 \mathrm{c}$, the PE specie was assigned as PE 16:0a/18:1. The mass spectrum in Figure $2 \mathrm{c}$ is representative of the less abundant PE species analyzed in this study, in which fragment peaks representing the loss of one of the acyl groups from the molecular ion were not abundant enough to be detected above background noise. In total 11 species of PE (6 diacyl and 5 plasmalogen) were structurally assigned by in situ tissue analysis and are listed in Table 2.

Phosphatidylinositols are a class of acidic glycerophospholipids that are significant as intra-cellular messengers in organisms. Figure 3 contains product-ion spectra of (a) PI 38:4-H and (b) PI 36:4-H from the cerebellar cortex in negative ion mode with DHA ma- 

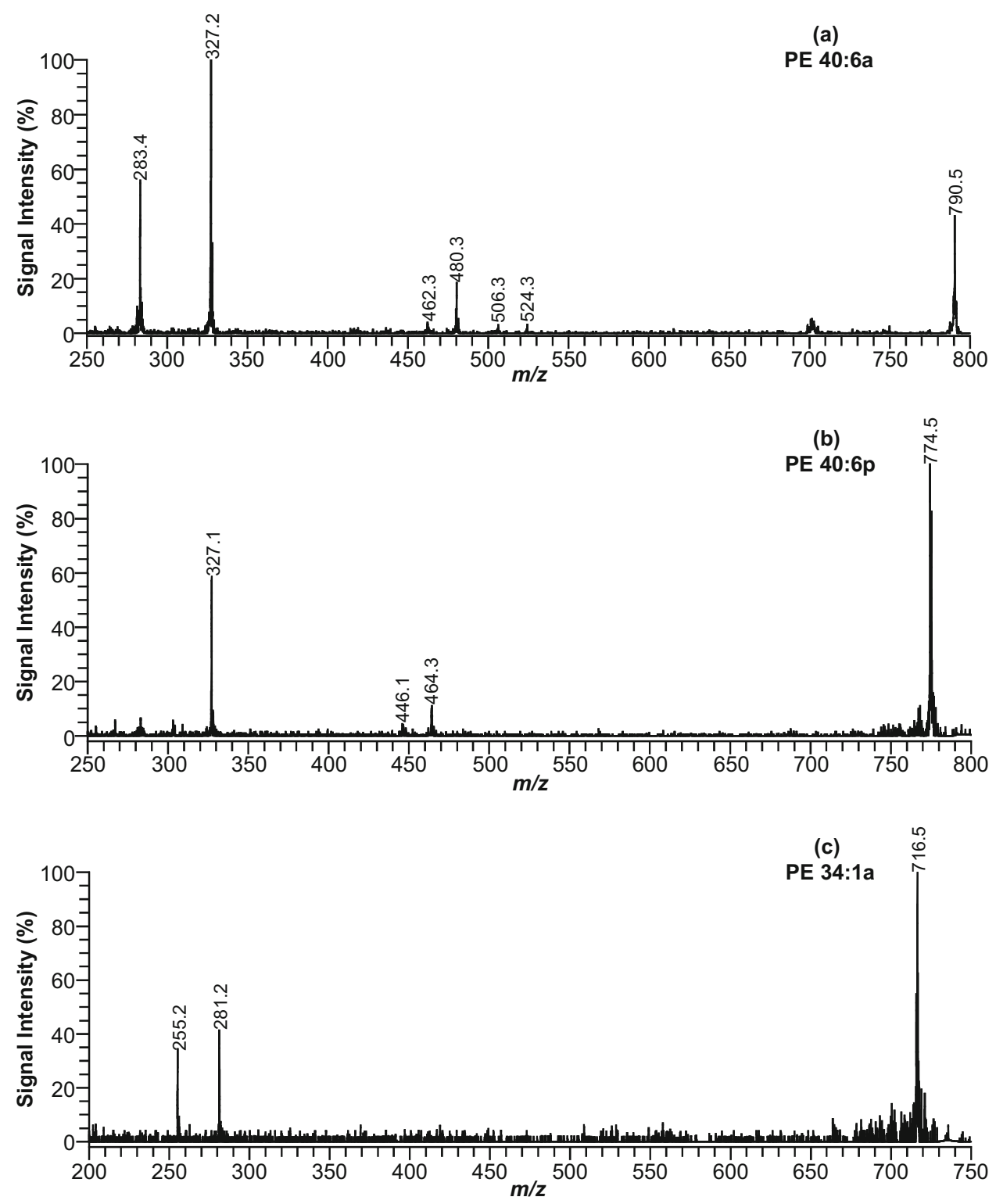

Figure 2. Product-ion spectra of (a) PE 40:6a-H mass peak, (b) PE 40:6p-H mass peak, and (c) PE 34:1a-H mass peak.

trix. The mass peak at $m / z 241$ (inositolphosphate $\mathrm{H}_{2} \mathrm{O}$ ) recorded in both Figure $3 \mathrm{a}$ and $3 \mathrm{~b}$, along with the mass peaks at $\mathrm{m} / \mathrm{z} 259$ (inositolphosphate) and 223 (inositolphosphate- $2 \mathrm{H}_{2} \mathrm{O}$ ) in Figure 3a confirm the presence of the inositol polar head group. Previous fragmentation studies using fast atom bombardment (FAB) [30], MALDI [31], and electrospray ionization (ESI) [32] have yielded similar peaks for PI species. Additionally, the carboxylate anions of the acyl groups for each specie was recorded at the following $\mathrm{m} / \mathrm{z}$ in Figure 3 (a) 283 (18:0) and 303 (20:4), (b) 255 (16:0) and 303 (20:4). Mass peaks, attributed to the loss of the acyl group at sn-2 $\left[\mathrm{M}-\mathrm{H}-\mathrm{R}_{2} \mathrm{CO}_{2} \mathrm{H}\right]^{-}$and the loss of the inositol head group and the fatty acid at sn-2 $\left[\mathrm{M}-\mathrm{H}-\mathrm{R}_{2} \mathrm{CO}_{2} \mathrm{H}-\mathrm{C}_{6} \mathrm{H}_{10} \mathrm{O}_{5}\right]^{-}$, were observed at 581 and 419 Da in Figure 3a and 553 and $391 \mathrm{Da}$ in Figure 3b. Based upon the product-ion spectra, PI species were assigned as follows in Figure 3: (a) 18:0-20:4 PI, (b) 16:0-20:4 PI. The positional assignments of acyl groups accordingly as sn- 1 or sn-2 substituent is based upon a previous fragmentation study, in which the relative abundance of ions corresponding to the loss of the sn-2 substituent is greater than the relative abundance of ions reflecting the loss of the sn-1 substituent [32].

Phosphatidylserines are a class of acidic glycerophospholipids that are important components of tissue membranes. Figure 4 contains product-ion spectra of (a) PS 40:6-H, (b) PS 38:1-H, and (c) PS 36:1-H from the cerebellar peduncle in negative ion mode with DHA matrix. The presence of $[\mathrm{M}-\mathrm{H}-87]^{-}$mass peaks in product-ion spectra, Figure 4 (a) $747.5 \mathrm{Da}$, (b) $729.5 \mathrm{Da}$, and (c) $701.5 \mathrm{Da}$, representing the loss of the serine head 

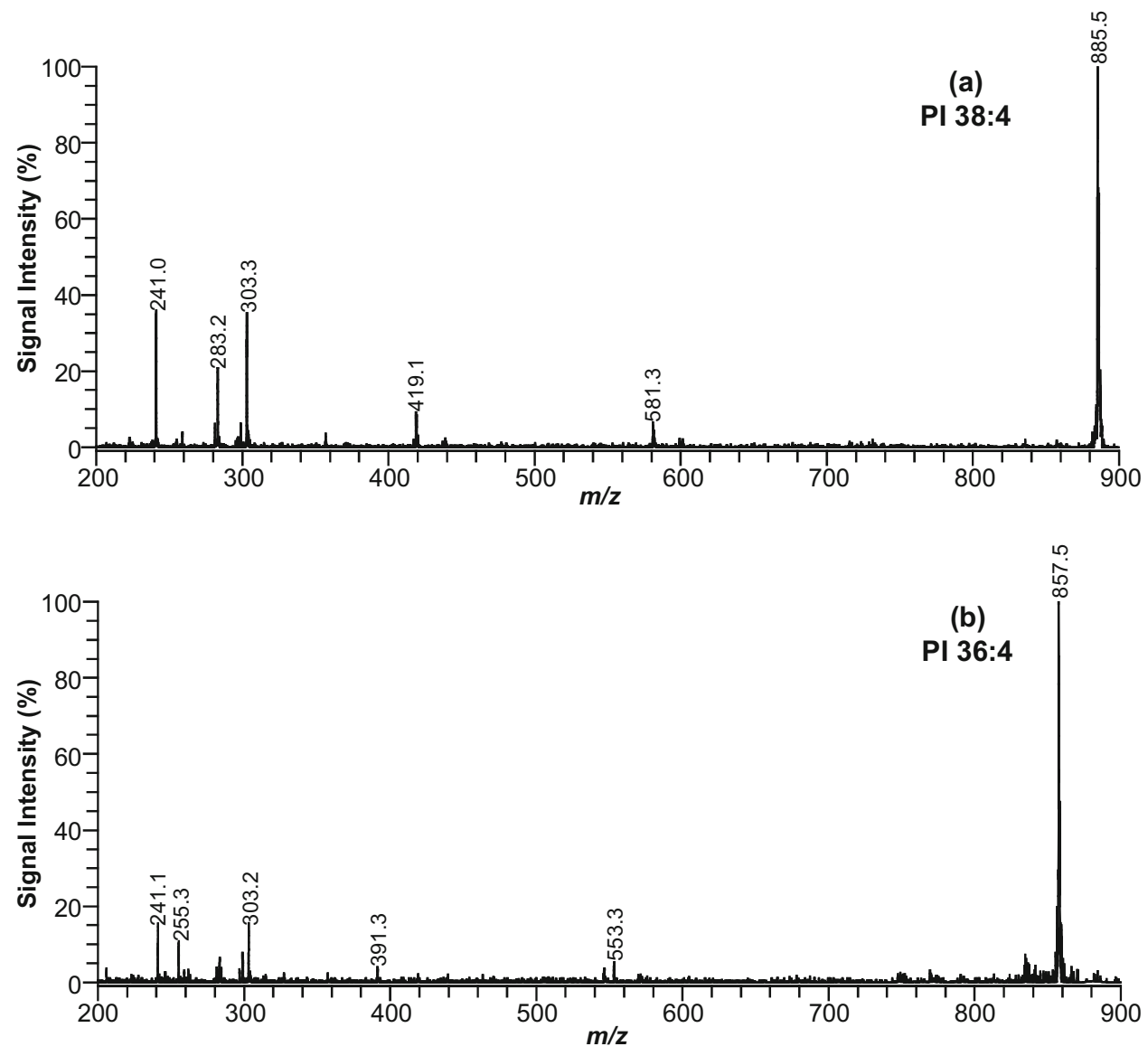

Figure 3. Product-ion spectra of (a) PI 38:4-H mass peak and (b) PI 36:4-H mass peak.

group, confirm the assignment of PS species. Several fragment peaks enabling the identification of the PS species in Figure 4 were recorded. A mass peak at 419 $m / z,\left[\mathrm{M}-\mathrm{H}-\mathrm{C}_{3} \mathrm{H}_{5} \mathrm{NO}_{2}-\mathrm{R}_{2} \mathrm{CO}_{2} \mathrm{H}\right]^{-}$corresponding to the loss of the serine head group and the acyl group at sn-2 was observed for all PS species in Figure 4. Additionally the carboxylate anions of the acyl groups for each specie was recorded at the following $m / z$ in Figure 4 (a) sn-1 283 (18:0) and sn-2 327 (22:6), (b) sn-1 283 (18:0) and sn-2 309 (20:1), and (c) sn-1 283 (18:0) and sn-2 281 (18:1). In Figure $4 \mathrm{a}$, mass peaks at $\mathrm{m} / \mathrm{z} 463$ and 437 were attributed to the loss of the serine head group and the acyl group at sn-1 and the loss of the serine head group and the acyl group at sn-2 as a ketene. Based upon the product-ion spectra, PS species were assigned as follows in Figure 4: (a) 18:0-22:6 PS, (b) 18:0-20:1 PS, and (c) 18:0-18:1 PS. Similar fragmentation patterns of PS species have been reported by FAB [33] and ESI [34]. The positional assignments of acyl groups accordingly as sn-1 or sn-2 substituent is based upon a previous fragmentation study, in which the $\mathrm{R}_{1} \mathrm{CO}_{2}{ }^{-}$ion is more abundant than the $\mathrm{R}_{2} \mathrm{CO}_{2}{ }^{-}$ion and the abundance of ions corresponding to the loss of the sn- 2 substituent is greater than the abundance of ions reflecting the loss of the sn-1 substituent [34]. A total of 6 PS species were structurally assigned by direct tissue analysis and are listed in Table 2.
Sulfatides are a class of sphingolipids with an additional sulfate group at the $3^{\prime}$ position of the galactose moiety in galactocerebroside and are major components of myelin. Figure 5 contains product-ion spectra of (a) ST 24:0 (OH)-H and (b) ST 24:0-H from the cerebellar peduncle in negative ion mode with $\mathrm{DHA}$ matrix. The presence of both $\mathrm{HSO}_{4}{ }^{-}(97 \mathrm{Da})$ and $\mathrm{SO}_{3}{ }^{-}(80 \mathrm{Da})$ in product-ion spectra in Figure 5 confirm the assignment of the mass peaks as sulfatides and was observed for every ST specie analyzed by MS/MS in Table 2. A previous FAB-MS study of sulfatides also recorded both fragment ions, $\mathrm{HSO}_{4}{ }^{-}(97 \mathrm{Da})$ and $\mathrm{SO}_{3}{ }^{-}(80 \mathrm{Da})$, and used them to differentiate sulfatides from phospholipids, which contain the fragment ions at $\mathrm{H}_{2} \mathrm{PO}_{4}{ }^{-}$(97 Da) and $\mathrm{PO}_{3}{ }^{-}(79 \mathrm{Da})$ [35]. Additional product-ions at 398 $\left(\mathrm{C}_{13} \mathrm{H}_{20} \mathrm{NO}_{10} \mathrm{~S}\right), 300\left(\mathrm{C}_{8} \mathrm{H}_{14} \mathrm{NO}_{9} \mathrm{~S}\right), 257$ (dehydrogenated galactose-sulfate, $\mathrm{C}_{6} \mathrm{H}_{9} \mathrm{O}_{9} \mathrm{~S}$ ), and $241 \mathrm{Da}$ (dehydrated galactose-sulfate, $\mathrm{C}_{6} \mathrm{H}_{9} \mathrm{O}_{8} \mathrm{~S}$ ), which further identify the ST head group, are also observed in both mass spectra in Figure 5. The only major difference in the production spectra in Figure 5 is the mass peak at $\mathrm{m} / \mathrm{z} 540$ observed for ST 24:0 (OH). This peak corresponds to the loss of the acyl chain in ST 24:0 (OH) and allows for the assignment of the ST specie in Figure 5a as d18:1/h24:1. This result was observed for all ST species with a hydroxyl fatty acyl group and permitted their structural assignment listed in Table 2. For ST species without a 

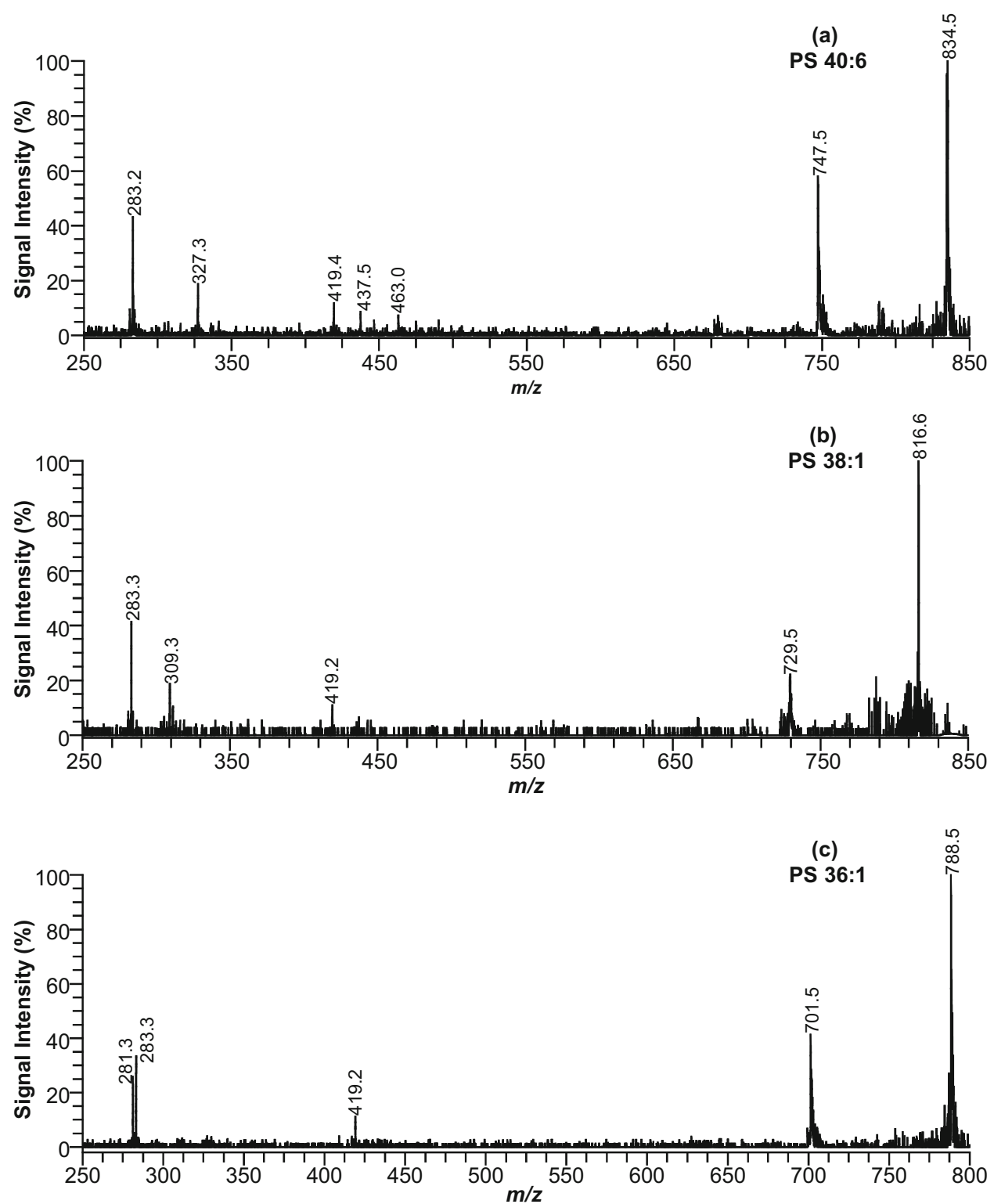

Figure 4. Product-ion spectra of (a) PS 40:6-H mass peak, (b) PS 38:1-H mass peak, and (c) PS 36:1-H mass peak.

hydroxyl group on their fatty acyl chain no mass peaks corresponding to chain length were observed. Thus for these species product-ion spectra only provided the identification of these species as sulfatides. Similar results for hydroxyl and non-hydroxyl ST species have been observed with FAB [35] and ESI [36-38].

One drawback for in situ tissue analysis of lipids is the complex product-ion spectra generated when more than one lipid species is present in significant amounts in the mass selection range. A good example of this is the PE 38:6a and PS 34:0 species. As listed in Table 1, the theoretical monoisotopic masses for the $[\mathrm{M}-\mathrm{H}]^{-}$mass peak of these species are as follows: PE 38:6a $(762.51 \mathrm{Da})$ and PS 34:0 (762.53 Da). With our current experimental conditions, we are able to get mass resolution greater than 8000 for the lipid species assigned in Figure 1.
However, this is inadequate for differentiating between the two species. Figure 6 illustrates a product-ion spectrum of the mass peak at $m / z 762.5$ from the cerebellar cortex in negative ion mode with DHA matrix. Several significant fragment peaks associated with both PE 38:6a and PS 34:0 were observed and are listed in Table 2. The mass peaks at 452, 435, 327 and $255 \mathrm{Da}$ are attributed to PE 38:6a and are assigned as follows: 452 $\left[\mathrm{M}-\mathrm{H}-\mathrm{R}_{2}{ }^{\prime} \mathrm{CH}=\mathrm{C}=\mathrm{O}^{-}, 435\left[\mathrm{M}-\mathrm{H}-\mathrm{R}_{2} \mathrm{CO}_{2} \mathrm{H}\right]^{-}, 327\right.$ $\left[\mathrm{C}_{22} \mathrm{H}_{31} \mathrm{O}_{2}\right]^{-}$and $255\left[\mathrm{C}_{16} \mathrm{H}_{31} \mathrm{O}_{2}\right]^{-}$. Fragment peaks corresponding to PS 34:0 were recorded at $675,437,419$, 283, and $255 \mathrm{Da}$ and are assigned as follows: 675 $\left[\mathrm{M}-\mathrm{H}-\mathrm{C}_{3} \mathrm{H}_{5} \mathrm{NO}_{2}\right]^{-}, 437\left[\mathrm{M}-\mathrm{H}-\mathrm{C}_{3} \mathrm{H}_{5} \mathrm{NO}_{2}-\mathrm{R}_{2}{ }^{\prime} \mathrm{CH}=\mathrm{C}=\right.$ $\mathrm{O}^{-}, 419\left[\mathrm{M}-\mathrm{H}-\mathrm{C}_{3} \mathrm{H}_{5} \mathrm{NO}_{2}-\mathrm{R}_{2} \mathrm{CO}_{2} \mathrm{H}\right]^{-}, 283\left[\mathrm{C}_{18} \mathrm{H}_{35} \mathrm{O}_{2}\right]^{-}$ and $255\left[\mathrm{C}_{16} \mathrm{H}_{31} \mathrm{O}_{2}\right]^{-}$. As stated above the acyl groups in PE species were assigned based upon the results of the 

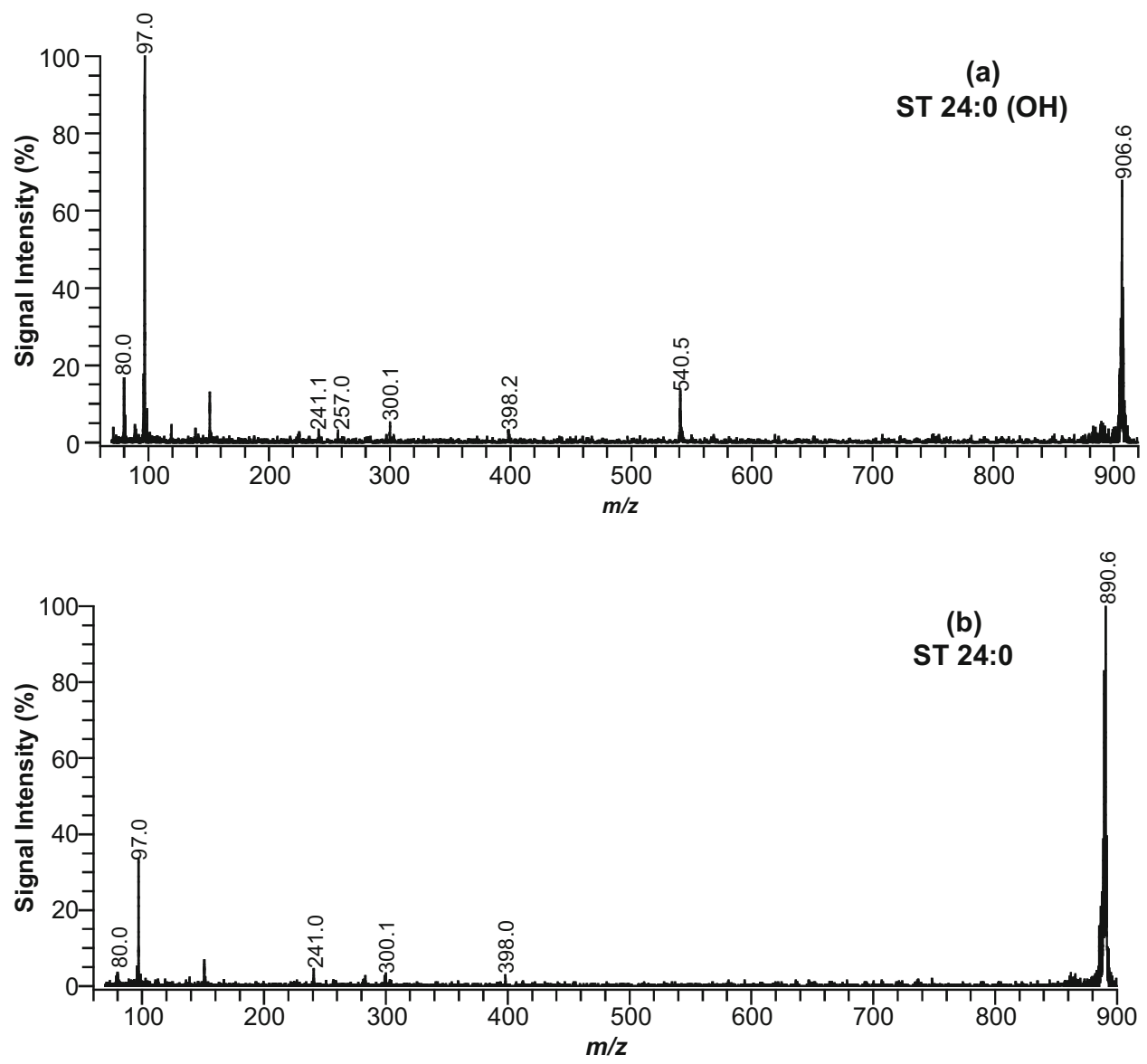

Figure 5. Product-ion spectra of (a) ST 24:0 (OH)-H mass peak and (b) ST 24:0-H mass peak.

$\mathrm{R}_{2} \mathrm{CO}_{2}{ }^{-}$ion being more abundant than the $\mathrm{R}_{1} \mathrm{CO}_{2}{ }^{-}$ion and the abundance of ions corresponding to the loss of the sn- 2 substituent being greater than the abundance of ions reflecting the loss of the sn-1 substituent, while the acyl groups in PS species were assigned based upon the observations of the $\mathrm{R}_{1} \mathrm{CO}_{2}{ }^{-}$ion being more abundant than the $\mathrm{R}_{2} \mathrm{CO}_{2}{ }^{-}$ion and the abundance of ions corresponding to the loss of the sn- 2 substituent being greater than the abundance of ions reflecting the loss of the sn- 1 substituent. The mass peaks attributed to PE 38:6a agree with this fragmentation pattern and lead to the assignment of the specie as PE 16:0a/22:6. However, the mass peaks corresponding to PS 34:0 correlate to two different assignments. Based upon the abundance of the carboxylate anions the assignment would be PS 16:0/18:0, while based upon the abundance of ions reflecting the loss of the sn-2 substituent the assignment would be PS 18:0/16:0. The contradiction is most likely

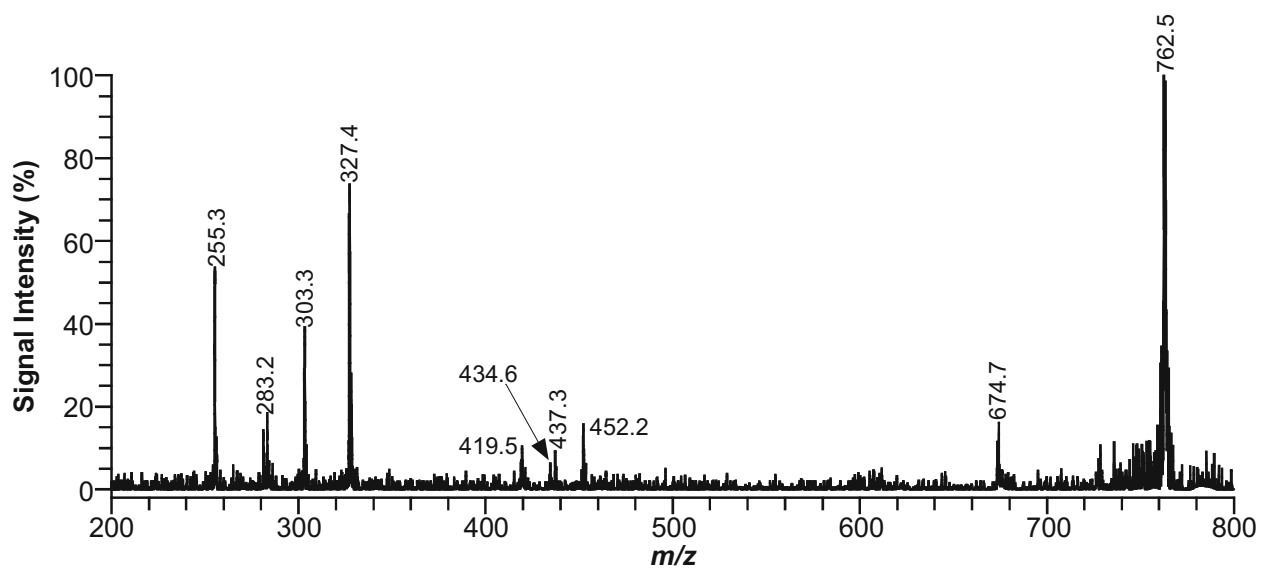

Figure 6. Product-ion spectra of mass peak at $m / z 762.5$. 
attributable to PE 38:6a also producing a fragment peak at $255 \mathrm{Da}$ thus making it greater than the mass peak at 283 Da which is only attributed to PS 34:0. Thus the most reasonable assignment of PS 34:0 should be PS 18:0/16:0. Further complicating this product-ion spectrum is the mass peak at $\mathrm{m} / \mathrm{z} 303$, which is assigned as the carboxylate anion, $\left[\mathrm{C}_{20} \mathrm{H}_{31} \mathrm{O}_{2}\right]^{-}$. This peak does not correspond to either PE 38:6a or PS 34:0 and is probably due to interference from PE 38a:4 in the mass selection range. Because of this complex product-ion spectrum, we are only able to tentatively assign the acyl group positions for PE 38:6a and PS 34:0.

\section{Conclusions}

In this study, a method for the in situ detection and structural characterization of glycerophospholipids (PE, PI, PS) and sulfatide species in brain tissue was developed using a MALDI-TOF/TOF mass spectrometer. Tandem MS analysis in negative ion mode yielded product-ion spectra that allowed for the identification of the lipid class head group and in most cases allowed for the identification and positional assignment of acyl/alkenyl groups. Future studies will focus on improving the fragmentation of lipid species through the use of alkaline adducts or different collision gases to yield more structural information particularly for non-hydroxyl ST species.

\section{Acknowledgments}

This research was supported by the Intramural Research Program of the National Institute on Drug Abuse, NIH. The authors thank the Office of National Drug Control Policy (ONDCP) for instrumentation funding, without which this and other projects could not have been accomplished.

\section{References}

1. Agranoff, B. W.; Benjamins, J. A.; Hajra, A. K. 1999; Siegel, G. J.; Agranoff, B.W.; Albers, R.W.; Fisher, S.K.; Uhler, M.D., eds.; In Basic Neurochemistry Molecular, Cellular, and Medical Aspects, 6th ed.; pp 47-67.Lippincott Williams and Wilkins: Philadelphia,

2. Piomelli, D. The Challenge of Brain Lipidomics. Prostaglandins Other Lipid Mediat. 2005, 77, 23-34.

3. Wenk, M. R. The Emerging Field of Lipidomics. Nat. Rev. Drug Discov. 2005, 7, 594-610.

4. Serhan, C. N. Mediator Lipidomics. Prostaglandins Other Lipid Mediat. 2005, 77, 4-14.

5. van Meer, G. Cellular Lipidomics. EMBO J. 2005, 24, 3159-3165.

6. Irizarry, M. C. A Turn of the Sulfatide in Alzheimer's Disease. Ann. Neurol. 2003, 54, 7-8.

7. Han, X.; Holtzman, D. M.; McKeel, D. W., Jr.; Kelley, J.; Morris, J. C. Substantial Sulfatide Deficiency and Ceramide in Very Early Alzheimer's Disease: Potential Role in Disease Pathogenesis. J. Neurochem. 2002, 82, 809-818.

8. Kakela, R.; Somerharju, P.; Tyynela, J. Analysis of Phospholipid Molecular Species in Brains from Patients with Infantile and Juvenile Neuronal-Ceroid Lipofuscinosis Using Liquid Chromatography-Electrospray Ionization Mass Spectrometry. J. Neurochem. 2003, 84, 1051-1065.

9. He, X.; Chen, F.; McGovern, M. M.; Schuchman, E. H. A FluorescenceBased, High-Throughput Sphingomyelin Assay for the Analysis of Niemann-Pick Disease and Other Disorders of Sphingomyelin Metabolism. Anal. Biochem. 2002, 306, 115-123.

10. Murphy, R. C. Mass Spectrometry of Phospholipids; Illuminati: Denver, 2002; Chapter II.

11. Schwartz, S. A.; Reyzer, M. L.; Caprioli, R. M. Direct Tissue Analysis Using Matrix-Assisted Laser Desorption/Ionization Mass Spectrometry: Practical Aspects of Sample Preparation. J. Mass Spectrom. 2003, 38, 699-708.

12. Chaurand, P.; Caprioli, R. M. Direct Profiling and Imaging of Peptides and Proteins from Mammalian Cells and Tissue Sections by Mass Spectrometry. Electrophoresis 2002, 23, 3125-3135.
13. Todd, P. J.; Schaaff, T. G.; Chaurand, P.; Caprioli, R. M. Organic Ion Imaging of Biological Tissue with Secondary Ion Mass Spectrometry and Matrix-Assisted Laser Desorption/Ionization. J. Mass Spectrom. 2001, 36, 355-369.

14. Rujoi, M.; Estrada, R.; Yappert, M. C. In Situ MALDI-TOF MS Regional Analysis of Neutral Phospholipids in Lens Tissue. Anal. Chem. 2004, 76, 1657-1663.

15. Touboul, D.; Piednoel, H.; Voisin, V.; De La. Porte, S.; Brunelle, A.; Halgand, F.; Laprevote, O. Changes in Phospholipid Composition Within the Dystrophic Muscle by Matrix-Assisted Laser Desorption/ Ionization Mass Spectrometry and Mass Spectrometry Imaging. Eur. J. Mass Spectrom. 2004, 10, 657-664.

16. Jackson, S. N.; Wang, H.-Y. J.; Woods, A. S.; Ugarov, M.; Egan, T.; Schultz, J. A. Direct Tissue Analysis of Phospholipids in Rat Brain Using MALDI-TOFMS and MALDI-Ion Mobility-TOFMS. J. Am. Soc. Mass Spectrom. 2005, 16, 133-138.

17. Jackson, S. N.; Wang, H.-Y. J.; Woods, A. S. Direct Profiling of Lipid Distribution in Brain Tissue Using MALDI-TOFMS. Anal. Chem. 2005, $77,4523-4527$.

18. Jones, J. J.; Borgmann, S.; Wilkins, C. L.; O'Brien, R. M. Characterizing the Phospholipid Profiles in Mammalian Tissues by MALDI FTMS. Anal. Chem. 2006, 78, 3062-3071.

19. Jackson, S. N.; Wang, H.-Y. J.; Woods, A. S. In Situ Structural Characterization of Phosphatidylcholines in Brain Tissue Using MALDI-MS/ MS. J. Am. Soc. Mass Spectrom. 2005, 16, 2052-2056.

20. Garrett, T. J.; Yost, R. A. Analysis of Intact Tissue by IntermediatePressure MALDI on a Linear Ion Trap Mass Spectrometer. Anal. Chem. 2006, 78, 2465-2469.

21. Yergey, A. L.; Coorssen, J. R.; Backlund, P. S., Jr.; Blank, P. S. Humphrey, G. A.; Zimmerberg, J.; Campbell, J. M.; Vestal, M. L. De Novo Sequencing of Peptides Using MALDI/TOF-TOF. J. Am. Soc. Mass Spectrom. 2002, 13, 784-791.

22. Paxinos, G.; Watson, C. The Rat Brain in Stereotaxic Coordinates, 3rd ed.; Academic Press: San Diego, 1997.

23. Sjovall, P.; Lausmaa, J.; Johansson, B. Mass Spectrometric Imaging of Lipids in Brain Tissue. Anal. Chem. 2004, 76, 4271-4278.

24. Suzuki, K. In Basic Neurochemistry, 1st ed.; Albers, R. W., Eds.; Little, Brown and Company: Boston, 1972; 207-227.

25. Kino, M.; Matsumura, T.; Gamo, M.; Saito, K. Studies on Molecular Species of Choline and Ethanolamine Glycerophospholipids Obtained from Rat Brain Myelin and Synaptosomes by Gas-Liquid Chromatography Mass Spectrometry. Biomed. Mass Spectrom. 1982, 9, 363-369.

26. Han, X.; Holtzman, D. M.; McKeel, D. W., Jr. Plasmalogen Deficiency in Early Alzheimer's Disease Subjects and in Animal Models: Molecular Characterization Using Electrospray Ionization Mass Spectrometry. J. Neurochem. 2001, 77, 1168-1180.

27. Han, X.; Gross, R. W. Structural Determination of Picomole Amounts of Phospholipids via Electrospray Ionization Tandem Mass Spectrometry. J. Am. Soc. Mass Spectrom. 1995, 6, 1202-1210.

28. Brouwers, J. F. H. M.; Vernooij, E. A. A. M.; Tielens, A. G. M.; van Golde, L. M. G. Rapid Separation and Identification of Phosphatidylethanolamine Molecular Species. J. Lipid Res. 1999, 40, 164-169.

29. Hsu, F.-F.; Turk, J. Charge-Remote and Charge-Driven Fragmentation Processes in Diacyl Glycerophosphoethanolamine Upon Low-Energy Collisional Activation: A Mechanistic Proposal. J. Am. Soc. Mass Spectrom. 2000, 11, 892-899.

30. Jensen, N. J.; Tomer, K. B.; Gross, M. L. FAB MS/MS for Phosphatidylinositol, -glycerol, -ethanolamine, and Other Complex Phospholipids. Lipids 1987, 22, 480-489.

31. Marto, J. A.; White, F. M.; Seldomridge, S.; Marshall, A. G. Structural Characterization of Phospholipids by Matrix-Assisted Laser Desorption/Ionization Fourier Transform Ion Cyclotron Resonance Mass Spectrometry. Anal. Chem. 1995, 67, 3979-3984.

32. Hsu, F.-F.; Turk, J. Characterization of Phosphatidylinositol, Phosphatidylinositol-4-Phosphate, and Phosphatidylinositol-4,5-Bisphosphate by Electrospray Ionization Tandem Mass Spectrometry: A Mechanistic Study. J. Am. Soc. Mass Spectrom. 2000, 11, 986-999.

33. Jensen, N. J.; Tomer, K. B.; Gross, M. L. Fast Aatom Bombardment and Tandem Mass Spectrometry of Phosphatidylserine and Phosphatidylcholine. Lipids 1986, 21, 580-588.

34. Hsu, F.-F.; Turk, J. Studies on Phosphatidylserine by Tandem Quadrupole and Multiple Stage Quadrupole Ion-Trap Mass Spectrometry with Electrospray Ionization: Structural Characterization and the Fragmentation Processes. J. Am. Soc. Mass Spectrom. 2005, 16, 1510-1522.

35. Ohashi, Y.; Nagai, Y. Fast Atom Bombardment Chemistry of Sulfatide (3-Sulfo-Galactosylceramide). Carbohydr. Res. 1991, 221, 235-243.

36. Hsu, F.-F.; Bohrer, A.; Turk, J. Electrospray Ionization Tandem Mass Spectrometric Analysis of Sulfatide. Determination of Fragmentation Patterns and Characterization of Molecular Species Expressed in Brain and in Pancreatic Islets. Biochim. Biophys. Acta 1998, 1392, 202-216.

37. Marbois, B. N.; Faull, K. F.; Fluharty, A. L.; Raval-Fernandes, S.; Rome, L. H. Analysis of Sulfatide from Rat Cerebellum and Multiple Sclerosis White Matter by Negative Ion Electrospray Mass Spectrometry. Biochim. Biophys. Acta 2000, 1484, 59-70.

38. Turk, J.; Hsu, F.-F. Studies on Sulfatides by Quadrupole Ion-Trap Mass Spectrometry with Electrospray Ionization: Structural Characterization and the Fragmentation Processes that Include an Unusual Internal Galactose Residue Loss and the Classical Charge-Remote Fragmentation. J. Am. Soc. Mass Spectrom. 2004, 15, 536-546. 